\title{
Primary biliary cirrhosis and type II autoimmune polyglandular syndrome
}

\author{
Mark Ram Borgaonkar MD FRCPC, David Geoffrey Morgan MD FRCPC
}

\begin{abstract}
MR Borgaonkar, DG Morgan. Primary biliary cirrhosis and type II autoimmune polyglandular syndrome. Can J Gastroenterol 1999;13(9):767-770. A 45-year-old female was diagnosed with Hashimoto's thyroiditis in 1976 and Addison's disease in 1979. At that time, her antimitochondrial antibody (AMA) level was elevated at 1:32. She subsequently developed premature ovarian failure and type I diabetes mellitus. In 1996, she became jaundiced with a cholestatic enzyme pattern. AMA was positive at a titre of 1:256. A liver biopsy confirmed the diagnosis of primary biliary cirrhosis $(\mathrm{PBC})$. She underwent a liver transplantation in January 1998.

This is the first report of PBC in association with type II autoimmune polyglandular syndrome. The association of $\mathrm{PBC}$ with other organ-specific autoimmune diseases supports an immunemediated pathogenesis and may have implications in further studies of PBC.
\end{abstract}

Key Words: Autoimmune diseases; Polyglandular type II autoimmune syndrome; Primary biliary cirrhosis; Schmidt's syndrome

\section{Cirrhose biliaire primitive et syndrome polyglandulaire auto-immun de type II}

RÉSUMÉ : Une femme de 45 ans a reçu un diagnostic de thyroïdite de Hashimoto en 1976 et de maladie d'Addison en 1979. À l'époque, son taux d'anticorps antimitochondrial (AAM) était élevé, à 1:32. Elle a par la suite développé une insuffisance ovarienne précoce et un diabète sucré de type $\mathrm{I}$. En 1996, elle a présenté un ictère accompagné d'un tableau enzymatique cholostatique. L'AAM s'est révélé positif avec un titre de 1:256. Une biopsie hépatique a confirmé le diagnostic de cirrhose biliaire primitive (CBP). Elle a subi une transplantation hépatique en janvier 1998.

Il s'agit du premier cas de CBP associé au syndrome polyglandulaire auto-immun de type II. Le lien entre CBP et d'autres maladies auto-immunes spécifiques à certains organes permet de supposer une pathogenèse d'origine immune et pourrait influer sur la conduite d'autres études sur la CBP.
$\mathrm{P}$ rimary biliary cirrhosis (PBC) is a chronic autoimmune disorder characterized by inflammatory destruction of septal and interlobular bile ducts leading to intrahepatic cholestasis and ultimately cirrhosis. The type II autoimmune polyglandular (Schmidt's) syndrome (APS) consists of Addison's disease with type I diabetes mellitus and/or autoimmune thyroid disease (1). PBC has been associated with a variety of autoimmune disorders, particularly thyroid disease, keratoconjunctivitis sicca, scleroderma and polyarthri- tis (2). However, the association of PBC with type II APS has not been reported until now.

\section{CASE PRESENTATION}

A 24-year-old White female presented in 1976 with cold intolerance and weight gain. Antimicrosomal and antithyroglobulin antibodies were positive, and she was diagnosed with Hashimoto's thyroiditis. She had a prior history of nasal polyps, asthma and a cholecystectomy for gallstones. She

Department of Medicine, Division of Gastroenterology, McMaster University, Hamilton, Ontario

Correspondence: Mark Ram Borgaonkar, Department of Gastroenterology, Room 4W8, McMaster University Medical Centre, 1200 Main Street

West, Hamilton, Ontario L8N 325. Telephone 905-521-2100 ext 75255, fax 905-521-4958, e-mail borgaonk@FHS.McMaster.ca

Received for publication October 12, 1998. Accepted December 21, 1998 
TABLE 1

Biochemical parameters

\begin{tabular}{|c|c|c|c|}
\hline Variable & $\begin{array}{l}\text { December } \\
1979\end{array}$ & $\begin{array}{c}\text { January } \\
1996\end{array}$ & $\begin{array}{c}\text { January } \\
1997\end{array}$ \\
\hline AST, U/L (<35 U/L) & 43 & 114 & 107 \\
\hline $\mathrm{ALT}, \mathrm{U} / \mathrm{L}(<35 \mathrm{U} / \mathrm{L})$ & 34 & 173 & 194 \\
\hline ALP, U/L (30 to $120 \mathrm{U} / \mathrm{L})$ & 48 & 683 & 672 \\
\hline GGT, U/L (<35 U/L) & 20 & 1203 & 302 \\
\hline \multicolumn{4}{|l|}{ Bilirubin, $\mu \mathrm{mol} / \mathrm{L}$} \\
\hline Total $(2$ to $18 \mu \mathrm{mol} / \mathrm{L})$ & 15.4 & 35 & 122 \\
\hline Conjugated $(<4 \mu \mathrm{mol} / \mathrm{L})$ & 1.7 & 22 & 114 \\
\hline Albumin, g/L (36 to $52 \mathrm{~g} / \mathrm{L}$ ) & & 41 & \\
\hline INR (0.9 to 1.2$)$ & & 1.0 & \\
\hline Cholesterol, mmol/L (<5.2 mmol/L) & & & 9.29 \\
\hline Alpha-fetoprotein, $\mu \mathrm{g} / \mathrm{L}(<10 \mu \mathrm{g} / \mathrm{L})$ & & & 6 \\
\hline $\begin{array}{l}\text { Serum } B_{12}, \mathrm{pmol} / \mathrm{L} \text { (133 to } \\
\quad 500 \mathrm{pmol} / \mathrm{L})\end{array}$ & & 223 & \\
\hline Serum IgM, g/L (0.45 to $1.5 \mathrm{~g} / \mathrm{L})$ & & 7.96 & \\
\hline $\begin{array}{l}\text { Sodium, } \mathrm{mmol} / \mathrm{L}(135 \text { to } \\
\qquad 145 \mathrm{mmol} / \mathrm{L} \text { ) }\end{array}$ & 125 & & \\
\hline $\begin{array}{l}\text { Potassium, } \mathrm{mmol} / \mathrm{L} \text { (3.5 to } \\
5.0 \mathrm{mmol} / \mathrm{L} \text { ) }\end{array}$ & 5.4 & & \\
\hline Glucose, $\mathrm{mmol} / \mathrm{L}(3.5$ to $7.0 \mathrm{mmol} / \mathrm{L}$ ) & 2.6 & & \\
\hline
\end{tabular}

Normal values are in parentheses. ALP Alkaline phosphatase; ALT Alanine aminotransferase; AST Aspartate aminotransferase; GGT Gamma glutamyl transpeptidase; INR International normalized ratio; Ig Immunoglobulin

took no medications and had allergies to penicillin, erythromycin and sulpha compounds. She was a nonsmoker and did not consume alcohol. Her father had been diagnosed with type I diabetes mellitus at the age of 19 years, and a paternal cousin had rheumatoid arthritis. Her daughter has since been diagnosed with systemic lupus erythematosus.

In 1979 , at the age of 27 years, the patient presented with nausea, vomiting and fatigue. Her pulse was 120 beats/min with a blood pressure of $100 / 60 \mathrm{mmHg}$ lying and $90 / 60 \mathrm{mmHg}$ sitting. Hyperpigmentation and vitiligo were present. Initial laboratory data are shown in Table 1. Hyponatremia, hyperkalemia and hypoglycemia were noted, and a random cortisol level was less that $0.5 \mu \mathrm{g} / \mathrm{dL}$. Addison's disease was diagnosed, and her symptoms and biochemical abnormalities rapidly improved with corticosteroids. Antiadrenal antibodies were positive, and antimitochondrial antibody (AMA) was detected at 1:32. The results of other autoantibody testing over 17 years are shown in Table 2.

The human leukocyte antigen (HLA) typing was A1, A3, B8, B27 and C4. The patient's daughter was also tested and found to share the HLA A1/B8 haplotype.

In 1980, at the age of 28 years, the patient became amenorrheic. Serum luteinizing hormone and follicle stimulating hormone levels were elevated, a diagnosis of premature ovarian failure was made and hormone replacement therapy was initiated.

The patient next came to medical attention in 1993, at the age of 41 years, complaining of dyspepsia. Endoscopy documented esophagitis, and her symptoms improved with
TABLE 2

Summary of autoantibody testing (indirect immunofluorescence)

\begin{tabular}{lccc}
\hline Autoantibody & $\begin{array}{c}\text { December } \\
\mathbf{1 9 7 9}\end{array}$ & $\begin{array}{c}\text { August } \\
\mathbf{1 9 8 0}\end{array}$ & $\begin{array}{c}\text { April } \\
\mathbf{1 9 9 6}\end{array}$ \\
\hline Antimitochondrial & $1: 32$ & $1: 128$ & $1: 256$ \\
$\begin{array}{l}\text { Antinuclear (membranous) } \\
\text { Rheumatoid factor }\end{array}$ & $1: 512$ & $1: 4000$ & $>1: 500$ \\
$\begin{array}{l}\text { Anti-DNA } \\
\text { Acetylcholine receptor }\end{array}$ & Negative & & \\
$\begin{array}{l}\text { Antithyroglobulin } \\
\text { Antimicrosomal }\end{array}$ & Positive & & Positive \\
$\begin{array}{l}\text { Parietal cell } \\
\text { Adrenal } \\
\text { Intrinsic factor }\end{array}$ & Negative & & \\
$\begin{array}{l}\text { Extractable nuclear antigens } \\
\quad \text { (anti-Ro, anti-La, anti-jo-1, } \\
\quad \text { anti-Scl-70) }\end{array}$ & & Positive & \\
\begin{tabular}{l} 
Anticardiolipin \\
\hline
\end{tabular} & & Positive & \\
\hline
\end{tabular}

omeprazole $20 \mathrm{mg}$ once a day. There were no clinical manifestations of scleroderma; therefore, esophageal manometry and testing for anti-Scl-70 antibodies were not performed. Subsequent testing was negative for anti-Scl-70 in 1996. Gastric biopsies were negative for Helicobacter pylori, and there was no gastritis histologically.

In January 1996, at age 44 years, the patient presented with right upper quadrant pain, pruritus and weight loss. She was icteric and had a palpably enlarged right hepatic lobe. Biochemical parameters are shown in Table 1 . The predominant abnormality was elevated liver enzymes in a cholestatic pattern. Her AMA was positive at a titre of 1:256, and the antinuclear antibody (ANA) was positive at a titre greater than 1:500. Quantitative immunoglobulins demonstrated an elevated immunoglobulin M level of $7.96 \mathrm{~g} / \mathrm{L}$. Ferritin and ceruloplasmin levels were normal. Screening for hepatitis A, $B$ and $C$ viruses was negative.

A percutaneous liver biopsy showed periportal inflammation, bile duct destruction and fibrosis of the portal tracts but no cirrhosis (Figures 1,2). PBC was diagnosed, and treatment was initiated with ursodeoxycholic acid $500 \mathrm{mg}$ twice a day.

In April 1996, the patient presented with polyuria, polydipsia and weight loss. Investigations revealed hyperglycemia and ketosis in keeping with type I diabetes mellitus. She was not tested for anti-islet cell antibodies. Her symptoms improved with insulin therapy.

The patient continued to be jaundiced and fatigued with an abnormal liver profile (Table 1). An abdominal ultrasound demonstrated hepatosplenomegaly but no evidence of ductal dilation or choledocholithiasis. Results of thyroid function tests were normal. Endoscopy revealed grade I esophageal varices, and a small bowel biopsy was normal. In June 1997, at the age of 45 years, she was assessed for liver transplantation. In consultation with an immunologist, cyclosporine A was initiated in an attempt to treat her multi- 
system autoimmune phenomena. Two months later, she presented with hematemesis attributed to grade 4 esophageal varices. She had a successful liver transplantation in January 1998. The explanted liver weighed $2306 \mathrm{~g}$ and contained nodules up to $1 \mathrm{~cm}$ in diameter. Histologically, there was portal fibrosis and cirrhosis, bile ductopenia, peripheral bile ductular proliferation and mild lymphocytic infiltration of the portal areas. These features were in keeping with cirrhotic stage PBC.

\section{DISCUSSION}

$\mathrm{PBC}$ is a chronic liver disease of unknown cause. It occurs primarily in women between age 40 and 60 years. Cases before the age of 30 years are uncommon (3). Although the pathogenesis is not fully understood, abnormalities in cellular and humoral immunity have been well described (4). Aberrant expression of major histocompatibility complex class II molecules on the biliary epithelium has been demonstrated, and an antigen on the biliary luminal surface that cross-reacts with a monoclonal antibody to pyruvate dehydrogenase complex E2, the autoantigen of AMA $(3,5,6)$, has been identified. A genetic predisposition is suggested by a $14.9 \%$ familial incidence of PBC, although HLA associations are relatively weak (7). One report of case-clustering around a water reservoir (8) and another study showing a $19 \%$ prevalence of urinary tract infections in PBC patients (9) raise the possibility of an environmental factor. Stemerowicz et al (10) found significant cross-reactivity between AMA and antigens from Enterobacteriaceae, suggesting a bacterial etiology of PBC.

Schmidt (11), who found lymphocytic infiltration of the adrenal and thyroid glands in two autopsy specimens, first described APS in 1926. The syndrome is characterized by simultaneous autoimmunological responses against multiple endocrine and exocrine glands. Three distinct forms of APS are recognized. Type I APS is inherited in an autosomal recessive fashion and usually presents in infancy with chronic mucocutaneous candidiasis, Addison's disease and hypoparathyroidism. Important gastrointestinal manifestations include pernicious anemia in $13 \%$ and chronic active hepatitis in $12 \%$ of patients (12). Type II APS (Schmidt's syndrome) is an autosomal dominant condition with incomplete penetrance. It usually presents between the ages of 20 and 40 years and is two to three times more common in women than in men (1). This disorder is characterized by Addison's disease with type I diabetes mellitus and/or autoimmune thyroid disease. Pernicious anemia (1), celiac disease (12) and chronic active hepatitis (13) are rarely associated. Type III APS consists of autoimmune thyroid disease with either type I diabetes mellitus or Addison's disease in the absence of any other autoimmune disorders. Our patient initially met the criteria for type III APS in 1979 when she developed Addison's disease with Hashimoto's thyroiditis alone. However, the subsequent development of premature gonadal failure requires that she be classified as type II APS.

Our patient had the characteristic features of type II APS. The diagnosis of hypoadrenalism was confirmed using adre-

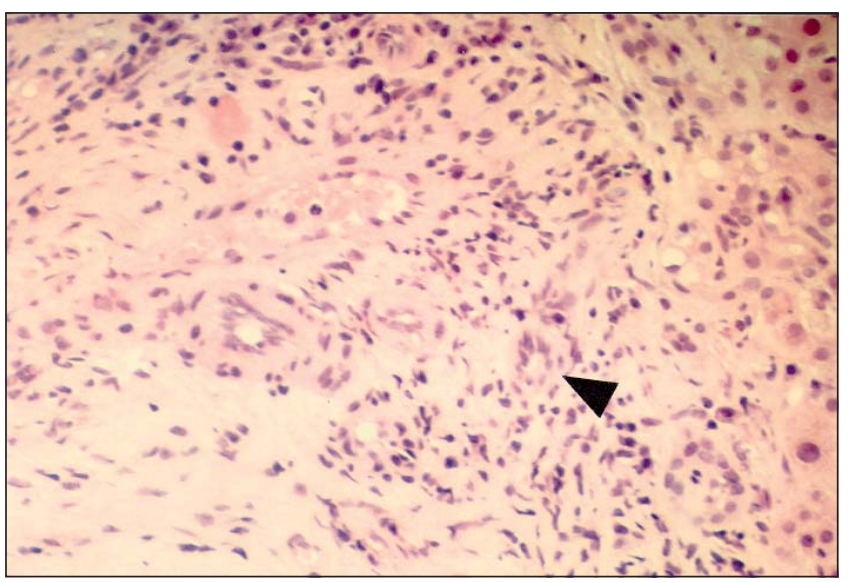

Figure 1) Photomicrograph of a histological section of liver showing inflammation in the portal tract and loss of bile ducts. Some proliferating bile ductules (arrrowhead) are seen peripherally (hemotoxylin and eosin, original magnification $\times 124)$

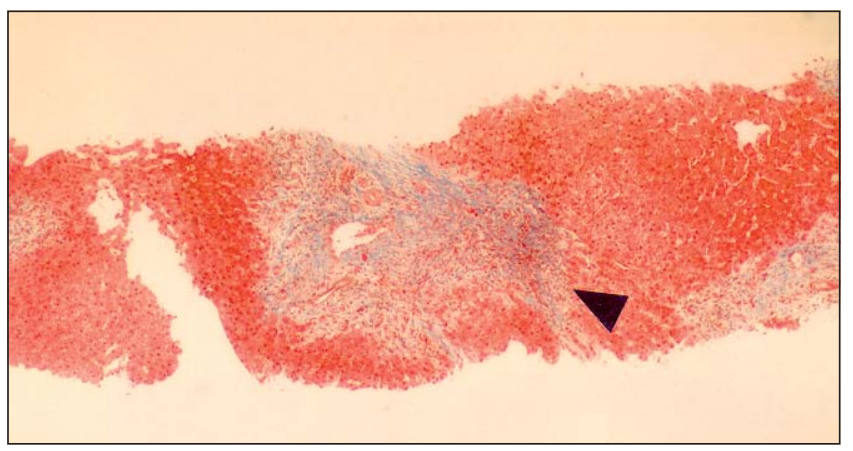

Figure 2) Photomicrograph of a histological section of liver showing fibrosis in the portal tracts (arrowhead) but no bridging (Trichrome, original magnification $\times 54$ )

nocorticotropic hormone stimulation testing, and the presence of antiadrenal antibodies supported an autoimmune etiology (14). Thyroid disorders and type I diabetes mellitus, as seen in our patient, are encountered in $69 \%$ and $52 \%$ of patients, respectively (15). Our patient also suffered from premature ovarian failure, which is a recognized component of type II APS in 4\% of patients (15). Parietal cell antibodies and acetylcholine receptor antibodies were also present but without clinical evidence of pernicious anemia or myasthenia gravis. A positive ANA and rheumatoid factor also occurred in the absence of clinical features of systemic lupus erythematosus or rheumatoid arthritis.

To our knowledge, the association of APS and PBC has been described only once previously. A 27-year-old male presented with type I diabetes mellitus and was diagnosed with PBC two years later on the basis of elevated alkaline phosphatase, positive AMA and a compatible liver biopsy (16). Hashimoto's thyroiditis, Sjögren's syndrome and hypogonadism were subsequently diagnosed. Antiparietal cell antibodies were positive, although the serum $B_{12}$ level was normal. This patient was somewhat unusual with features of both types I and II APS. The absence of Addison's disease does not allow him to be classified as type II APS, and the ab- 
sence of chronic mucocutaneous candidiasis is atypical for type I APS.

$\mathrm{PBC}$ is associated with other autoimmune disorders. Culp et al (2) reviewed 120 consecutive patients with $\mathrm{PBC}$ and found that $66 \%$ had keratoconjunctivitis sicca, 19\% polyarthritis, $18 \%$ scleroderma, $19 \%$ thyroid disease, $11 \%$ cutaneous disorders, $2 \%$ pernicious anemia and $1 \%$ inflammatory bowel disease (2). In total, $84 \%$ of the PBC patients in that series had at least one other autoimmune disease. However, there was no description of any association with polyendocrinopathies.

Our patient had a typical presentation of PBC with respect to the age of onset and symptomatology. One interesting feature of this case is that, in 1979, 17 years before her presentation and diagnosis of $\mathrm{PBC}$, she was AMA-positive at a titre of 1:32 and then again eight months later at a titre of 1:128. AMA is an immunoglobulin $G$ antibody directed against the E2 component of the mitochondrial pyruvate dehydrogenase complex on the inner mitochondrial membrane (4). The most commonly recognized epitope is the inner lipoyl domain, with the main contribution from residues 128 to 135,167 to 186 and 202 to 221 (3). This antibody is known to be up to $95 \%$ sensitive $(17-20)$ for PBC. Its presence 17 years before the onset of symptoms supports the contention that PBC has a long subclinical phase (3). This is consistent with the findings of Metcalf et al (21) who followed a cohort of 29 patients with AMA levels greater than

\section{REFERENCES}

1. Muir A, Maclaren NK. Autoimmune diseases of the adrenal glands, parathyroid glands, gonads, and hypothalamic-pituitary axis. Endocrinol Metab Clin North Am 1991;20:619-45.

2. Culp KS, Fleming CR, Duffy J, et al. Autoimmune associations in primary biliary cirrhosis. Mayo Clin Proc 1982;57:365-70.

3. Coppel RL, Gershwin ME. Primary biliary cirrhosis: the molecule and the mimic. Immunol Rev 1995;144:17-49.

4. Galperin C, Gershwin ME. Immunopathology of primary biliary cirrhosis. Baillieres Clin Gastroenterol 1996;10:461-81.

5. Van de Water J, Turchany J, Leung PS, et al. Molecular mimicry in primary biliary cirrhosis: evidence for biliary epithelial expression of a molecule cross-reactive with pyruvate dehydrogenase complex E2. J Clin Invest 1993;91:2653-64.

6. Joplin R, Lindsay JG, Johnson GD, Strain A, Neuberger J. Membrane dihydrolipoamide acetyl transferase (E2) on human biliary epithelial cells in primary biliary cirrhosis. Lancet 1992;339:93-4.

7. Gregory WL, Bassendine MF. Genetic factors in primary biliary cirrhosis. J Hepatol 1994;20:689-92.

8. Triger DR. Primary biliary cirrhosis: an epidemiological study. Br Med J 1980;281:772-5.

9. Burroughs AK, Rosenstein IJ, Epstein O, Hamilton-Miller JM, Brumfitt W, Sherlock S. Bacteriuria and primary biliary cirrhosis. Gut 1984;25:133-7.

10. Stemerowicz R, Hopf U, Moller B, et al. Are antimitochondrial antibodies in primary biliary cirrhosis induced by $\mathrm{R}$ (rough)-mutants of enterobacteriaceae? Lancet 1988;ii:1166-70.

11. Schmidt MB. Eine biglandulare Erkrankung (Nebennieren und Schilddruse) bei Morbus Addisonii. Verh Dtsch Ges Pathol 1926;21:212-21.

12. Weetman AP. Autoimmunity to steroid-producing cells and familial polyendocrine autoimmunity. Baillieres Clin Endocrinol Metab 1995;9:157-74.
1:40 but normal liver enzymes for 17 years. Twenty-two (76\%) of those patients developed symptoms of PBC, and 24 $(83 \%)$ developed abnormal liver enzymes during this time period $(21,22)$.

Another prominent feature of this case is the clustering of multiple, organ-specific autoimmune diseases in the same patient. Research on Addison's disease, Hashimoto's thyroiditis, premature ovarian failure and type I diabetes does not suggest that there is a common autoantigen among them or that there is any cross-reactivity with the PDC-E2 antigen $(12,13,23)$. This suggests that the occurrence of these autoimmune diseases in one patient represents a generalized predisposition or susceptibility to autoimmunity. Whether this is the result of a genetic predisposition, exposure to an environmental factor or both may be the subject of further study of PBC.

\section{CONCLUSION}

This patient with type II APS represents yet another autoimmune association with PBC. The clustering of these organspecific autoimmune disorders suggests an underlying defect toward autoimmunity, which may be relevant for further understanding of the pathogenesis of PBC.

ACKNOWLEDGEMENTS: The authors thank Dr John K Marshall for his helpful suggestions in the preparation of this manuscript.

13. Riley WJ. Autoimmune polyglandular syndromes. Horm Res 1992;38(Suppl 2):9-15.

14. Irvine WJ, Barnes EW. Addison's disease, ovarian failure and hypoparathyroidism. Clin Endocrinol Metab 1975;4:379-434.

15. Neufeld M, Maclaren NK, Blizzard RM. Two types of autoimmune Addison's disease associated with different polyglandular autoimmune (PGA) syndromes. Medicine 1981;60:355-62.

16. Ko GT, Szeto CC, Yeung VT, Chow CC, Chan H, Cockram CS. Autoimmune polyglandular syndrome and primary biliary cirrhosis. Br J Clin Pract 1996;50:344-6.

17. Coppel RL, McNeilage LJ, Surh CD, et al. Primary structure of the human M2 mitochondrial autoantigen of primary biliary cirrhosis: dihydrolipoamide acetyltransferase. Proc Natl Acad Sci USA $1988 ; 85: 7317-21$

18. Fussey SP, Guest JR, James OF, Bassendine MF, Yeaman SJ. Identification and analysis of the major M2 autoantigens in primary biliary cirrhosis. Proc Natl Acad Sci USA 1988;85:8654-8.

19. Van de Water J, Gershwin ME, Leung P, Ansari A, Coppel RL. The autoepitope of the $74-\mathrm{kD}$ mitochondrial autoantigen of primary biliary cirrhosis corresponds to the functional site of dihydrolipoamide acetyltransferase. J Exp Med 1988;167:1791-9.

20. Van de Water J, Cooper A, Surh CD, et al. Detection of autoantibodies to recombinant mitochondrial proteins in patients with primary biliary cirrhosis. N Engl J Med 1989;320:1377-80.

21. Metcalf JV, Mitchison HC, Palmer JM, et al. Natural history of early primary biliary cirrhosis. Lancet 1996;348:1399-1402.

22. Mitchison HC, Bassendine MF, Hendrick A, et al. Positive antimitochondrial antibody but normal alkaline phosphatase: is this primary biliary cirrhosis? Hepatology 1986;6:1279-84.

23. Betterle C, Volpato M, Greggio AN, Presotto F. Type 2 polyglandular autoimmune disease (Schmidt's syndrome). J Pediatr Endocrinol Metab 1996;9:113-23. 


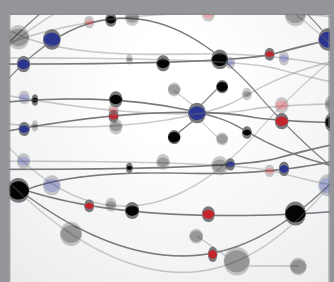

The Scientific World Journal
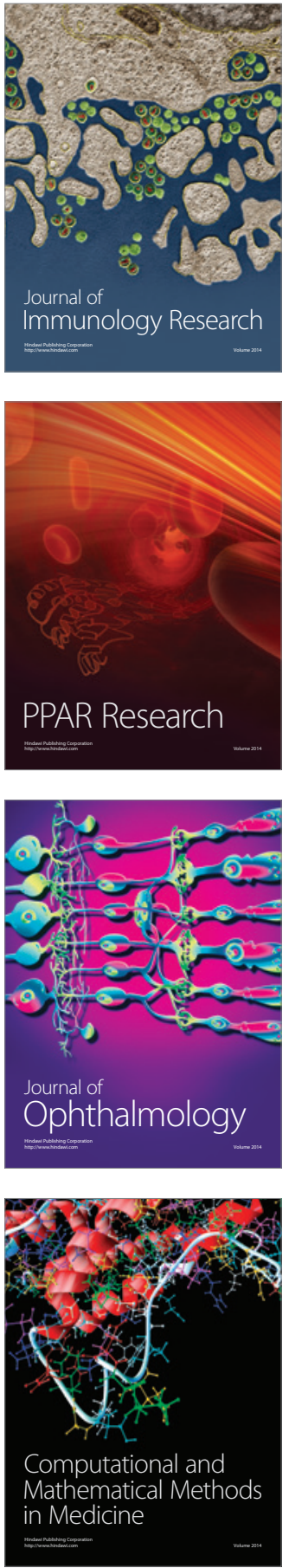

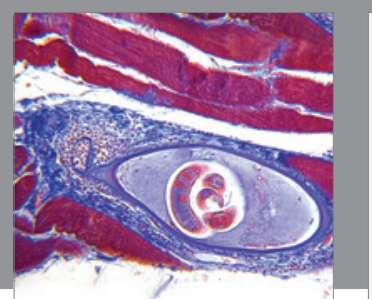

Gastroenterology Research and Practice

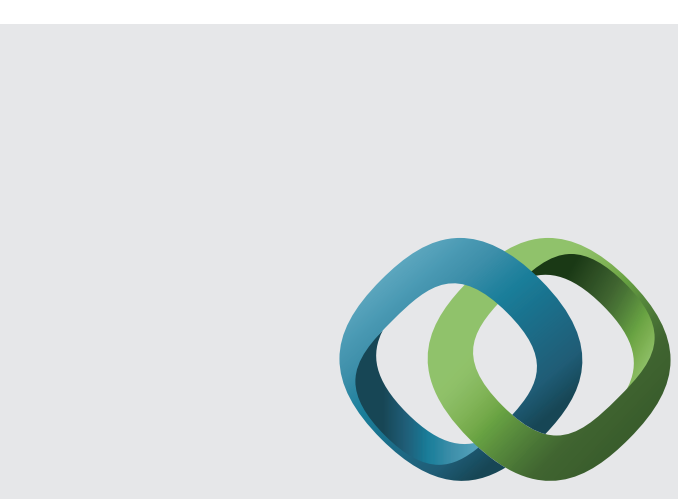

\section{Hindawi}

Submit your manuscripts at

http://www.hindawi.com
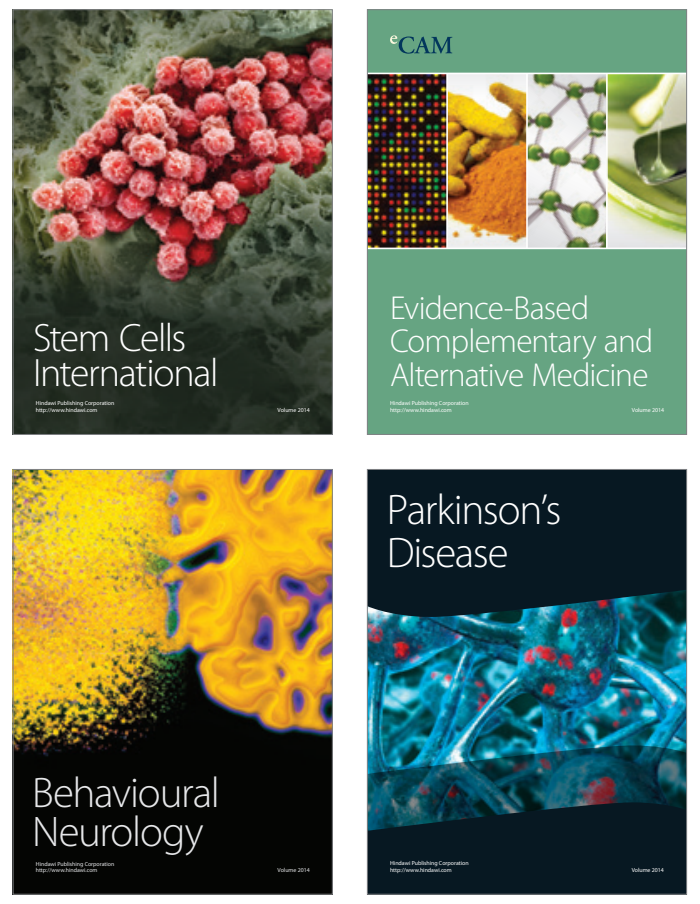
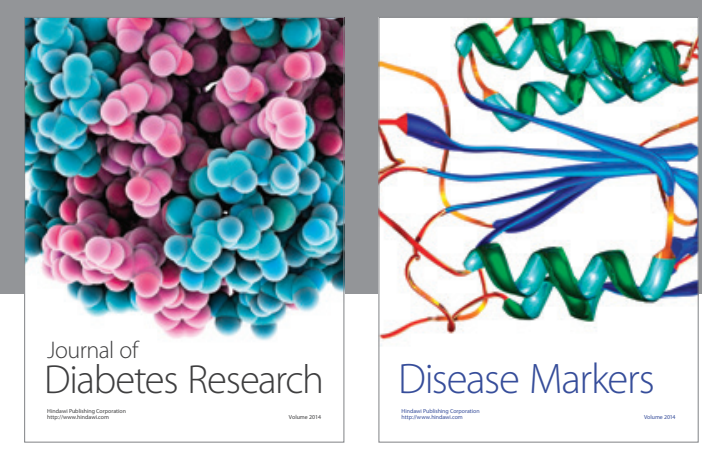

Disease Markers
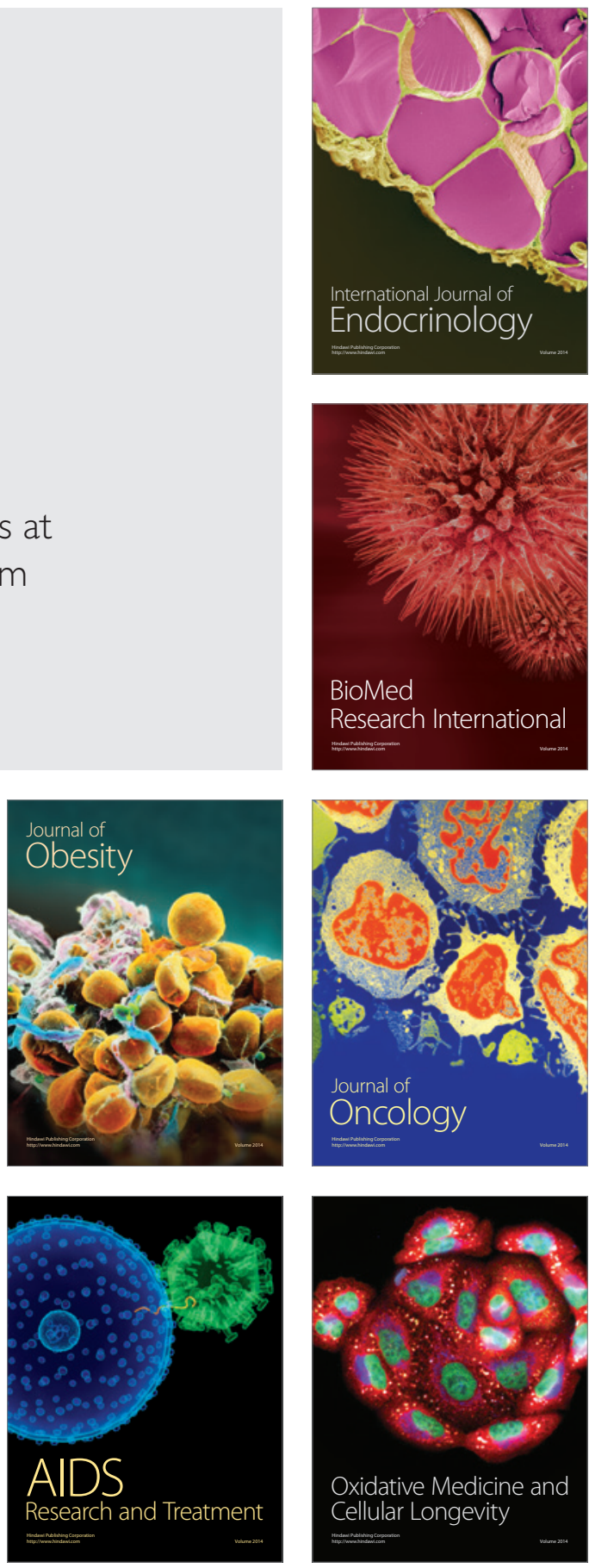